\title{
Medicinal mushroom Taiwanofungus camphoratus: A potential cure for cancer
}

\section{I-Shu Lee ${ }^{1,3}$, Roland Kirschner ${ }^{2}$, Shui-Tein Chen ${ }^{1,3}$}

${ }^{1}$ Antrodia cinnamomea Association of Taiwan Treasure, Taipei city, 106, Taiwan; ${ }^{2}$ Department of Biomedical Sciences and Engineering, National Central University, Taiwan; ${ }^{3}$ Institute of Biological Chemistry, Academia Sinica, Taiwan

Corresponding author: I-Shu Lee, Institute of Biological Chemistry, Academia Sinica, 128, Academia Road Sec. 2, Nankang, Taipei 115, Taiwan

Submission Date: October $27^{\text {th }}$, 2018. Acceptance Date: August $28^{\text {th }}$, 2019. Publication Date: August $31^{\text {st }}, 2019$.

Citation: Lee I., Kirschner R., Chen S. Medicinal Mushroom Taiwanofungus camphoratus: A potential cure for cancer. Functional Foods in Health and Disease 2019; 9(8): 508-520. DOI: https://doi.org/10.31989/ffhd.v9i8.576

\begin{abstract}
Based on traditional and folk medicine, mushrooms have been developed into anti-cancer therapeutics. In this article, a brief overview is given of the most important medical mushroom species and their specific anti-cancer functions and mechanisms. Taiwanofungus camphoratus (Antrodia cinnamomea), is a medical fungus chosen to examine the process from ethnomedicine to developing new products for the market based on scientific, analytic, and experimental evidence. The bioactive compounds have indirect effects in cancer treatment by benefiting the immune system as well as having direct cytotoxic effects on cancer cells.

Taiwanofungus camphoratus is a fungus endemic to Taiwan and one of the most popular known alternative remedies for liver cancer in Taiwan. To date, more than 150 liver cancer patients have survived using T. camphoratus. The treatment has caused tumor shrinking, as well as the disappearance of a tumor altogether in some cases. The ratio between male and female patients has been nearly equal, with ages ranging between $20-79$ years. The most effective candidates are those between the ages of $40-60$ years.
\end{abstract}


The complex mixture of bioactive compounds in natural fruit bodies is a challenge for artificial production in vitro. Particular problems in developing T. camphoratus into therapeutics for the global market are its rarity in nature and its close dependence on an endemic tree in Taiwan. These challenges can help promote new solutions which could be utilized in the future with other medical fungi

Keywords: Medicinal mushrooms, anti-cancer therapeutics, Taiwanofungus camphoratus, liver cancer.

\section{INTRODUCTION}

The use of mushrooms as therapeutics dates back to over 2000 years ago, including the use of Laricifomes officinalis in Europe and Ganoderma lingzhi in China. Fruitbodies of Piptoporus betulinus (Figure 1G) found among the items of "Ötzi the Iceman", a 5000-year-old European mummy, were presumably used as a remedy against parasitic worms [1]. The traditional usage of mushrooms in European folk medicine, e.g. of "Judas' Ear", Auricularia auricula-judae (Figure 1B) gradually disappeared in the $18^{\text {th }}$ and $19^{\text {th }}$ centuries [2]. Trametes versicolor (Figure 1I). In the West, mushrooms were used only for ornamental purposes, as opposed to the East where they were used as medicine. However, in comparison to the uninterrupted development and cultivation in East Asia for many centuries, the medical research and usage of mushrooms has experienced a relatively recent revival and development in Western countries. In traditional Chinese medicine and folk medicines, mushrooms have not been used specifically to treat cancer, but have been used for general disease prevention or to treat other diseases. For example, one of the most commonly used medical fungi in Chinese medicine is Wolfiporia cocos ("fu ling"). The antitumor properties of medical fungi were discovered mostly through screening them with modern scientific methods. In contrast to other diseases traditionally treated with medical mushrooms, there is little data for mushrooms and the treatment of cancer. Consequently, this may explain why few mushroombased anticancer therapeutics are available.

Nonetheless, scientific research devoted to anticancer properties of mushrooms started worldwide in the 1960s [2]. In this review, the recent development of a mushroom from Taiwan was examined to illustrate the process from ethnomedicine to new, science-based anticancer therapeutics. 

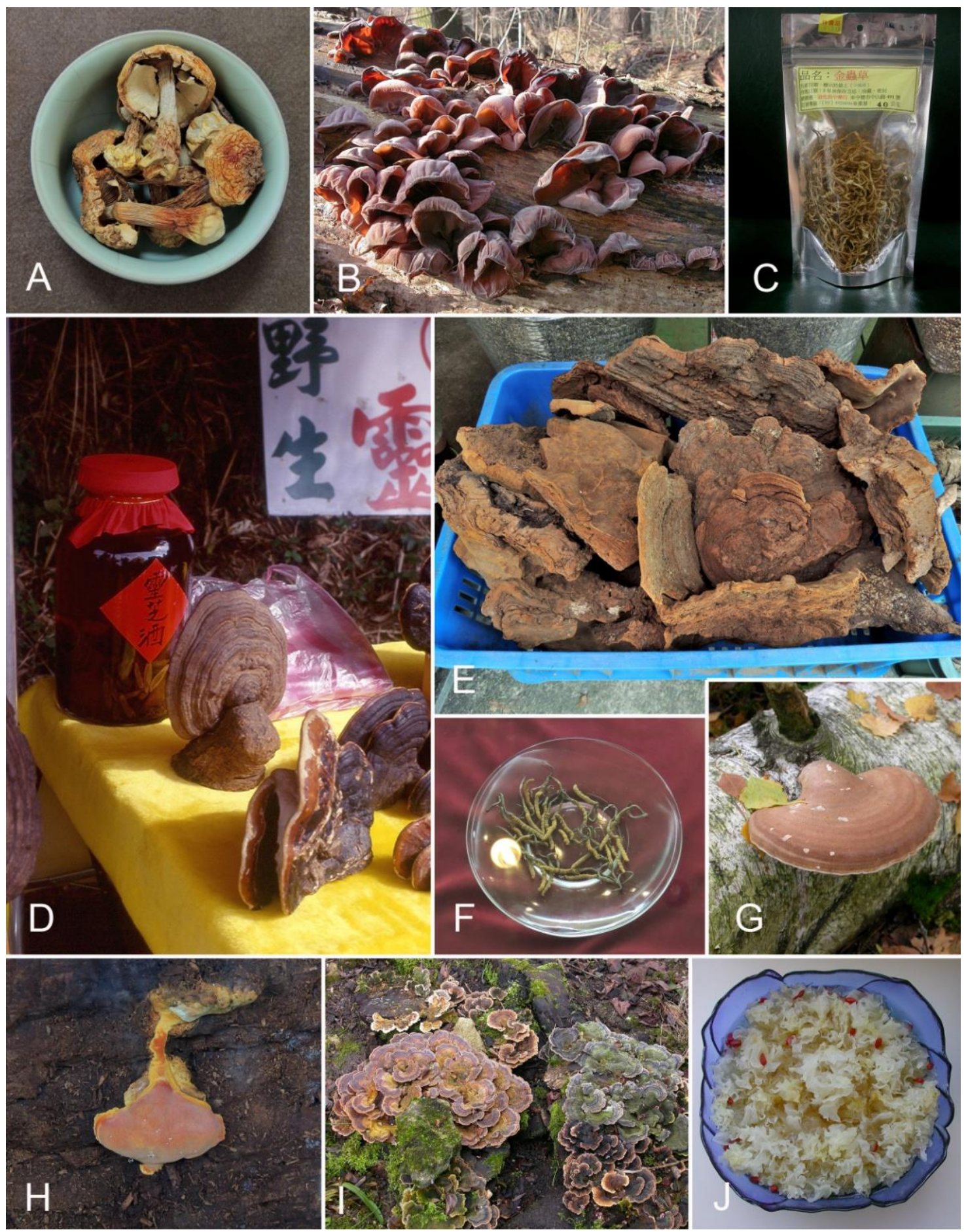

Figure 1. Examples of medical mushrooms with antitumor properties. A. Agaricus blazei, dried fruitbodies from the market. B. Auricularia auricula-judae on its natural wood substrate. C. Cordyceps militaris, ascostromata from artificial cultivation medium. D. Ganoderma species from wild collection sold on the market. E. Sanghuangporus sanghuang from the market. F. Ophiocordyceps sinensis, mummified caterpillars with ascostromata. G. Piptoporus betulinus on the natural wood substrate. H. Taiwanofungus camphoratus artificially grown on wood log. I. Trametes versicolor on the natural habitat. J. Dessert made of Tremella fuciformis from artificial cultivation and Lycium chinense (gouqi) berries. 


\section{HISTORY AND TRADITIONAL APPLICATION}

Taiwanofungus camphoratus is the most studied species of all the fungi with anti-cancer potential activity. Over 900 related scientific research reports have been published in international journals on the anti-cancer potential of T. camphoratus. The following text analyzes T. camphoratus as an example of a medical fungus to illustrate the general process from ethnomedicine to developing new products for the market based on scientific, analytical and experimental evidence.

Antrodia cinnamomea, also known as Antrodia camphorata or Taiwanofungus camphoratus, is a precious and unique edible fungus that grows naturally only on the aromatic tree Cinnamomum kanehirae (Lauraceae; Figure 2), which is native to Taiwan [3, 4]. Wild T. camphoratus grows between June and October at altitudes between 600 and $1800 \mathrm{~m}$. The mushroom prefers to grow on the inner wall inside cavities of old tree trunks. Some fruit bodies grow on moist surfaces of dead trees or on the stumps of cut trees. The growth rate of wild T. camphoratus mushroom is extremely slow. A ten year old fruit body has a dimension of only $25 \times 15 \times 12 \mathrm{~mm}$. The scarcity of the natural host and slow growth rate of the mushroom rendered this treasured mushroom as "ruby in Taiwanese forests".

T. camphoratus has been used medically by aboriginal tribes for centuries to treat diseases like food and drug intoxication, diarrhea, abdominal pain, hypertension, skin itching, and cancer [5]. The earliest record of a medical recipe against intoxication using T. camphoratus was given by the traditional Chinese medicine doctor Tsai in 1983 with the formula of the recipe reported in 1987 [6]. Scientific study of T. camphoratus started in 1990 and the first reports of its biological functions have been documented in National Digital Library of Theses and Dissertations in Taiwan [7]. Over the past decade, more than 300 papers and 150 Taiwan patent applications for $T$. camphoratus have been documented [8,9]. Numerous studies have been conducted on its physiology, biological, and pharmacological properties. Genomic and transcriptomic analyses of the medicinal fungus $T$. camphoratus have been reported [10]. A 32.15-Mb genome draft containing 9,254 genes was cloned and genome ontology enrichment and pathway analyses were studied to uncover the sexual development and the biosynthesis of sesquiterpenoids, triterpenoids, ergostanes, antroquinonol, and antrocamphin. 
Table 1. List of research about Taiwanofungus camphoratus, including synonyms and commercial names in brackets, classification, experimental anticancer evidence, detailed mechanisms, and references. Class $=$ Classification, $\mathrm{B}=$ Basidiomycota, $\mathrm{Po}=$ Polyporales .

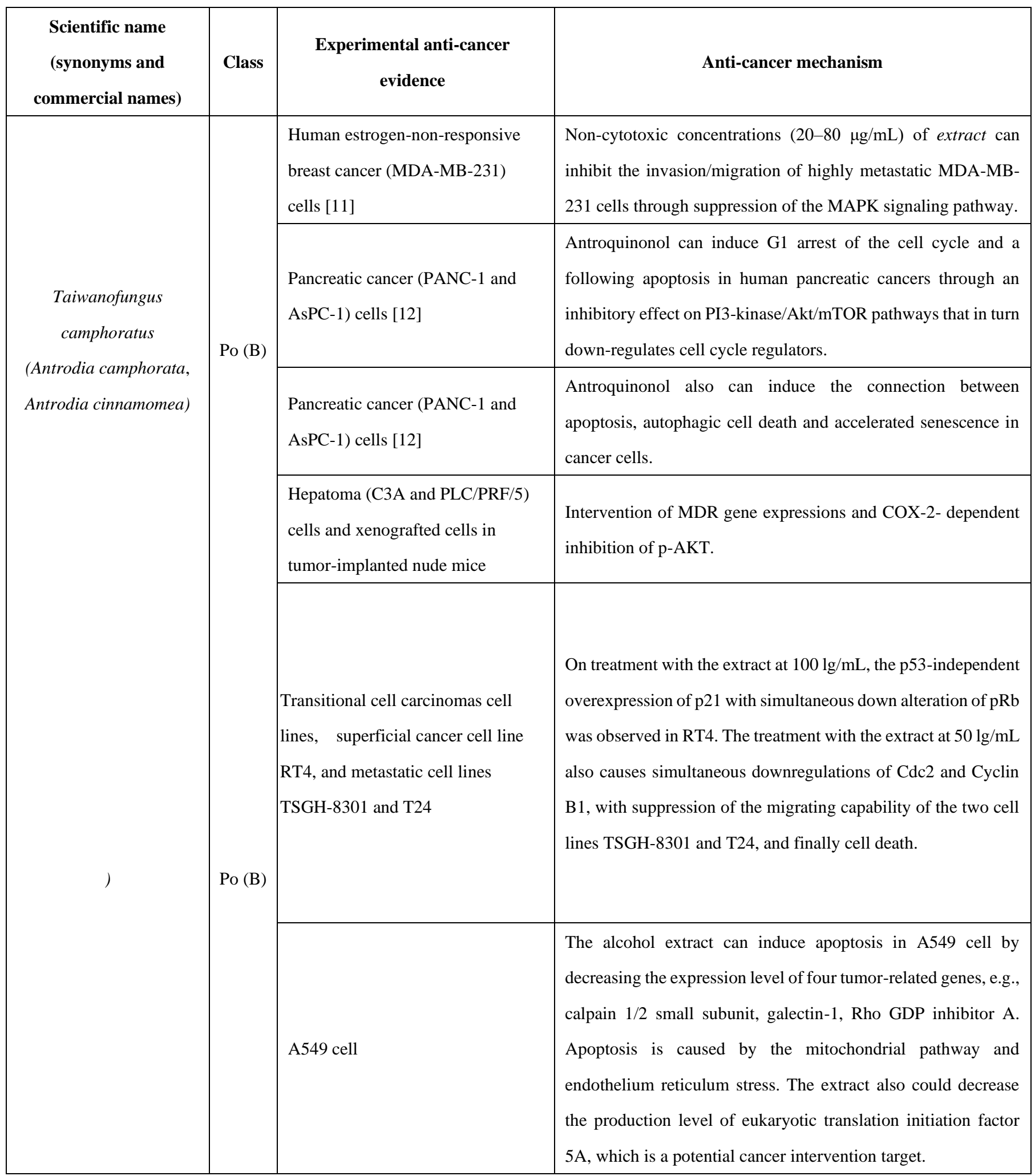




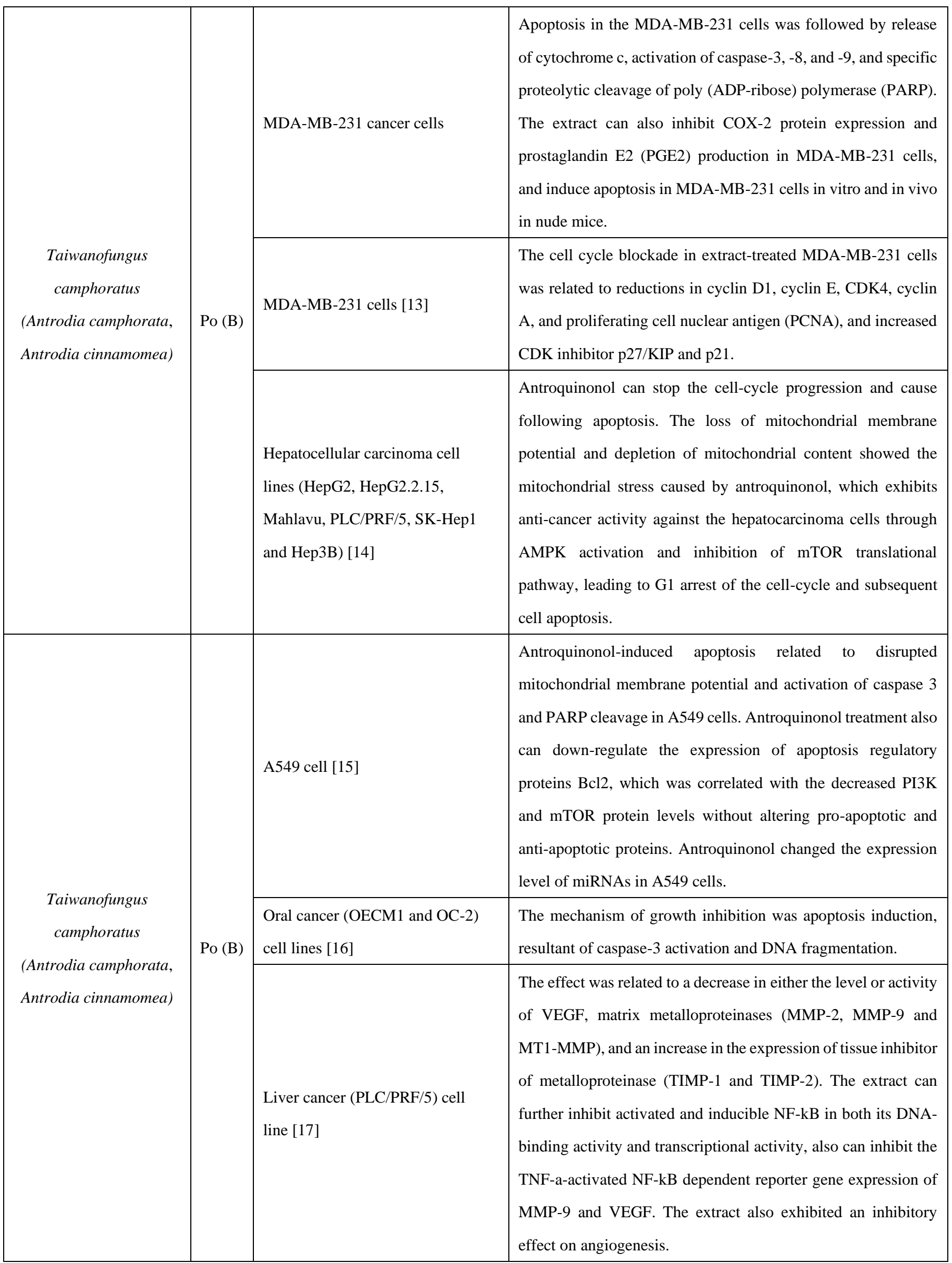




\section{MEDICINAL USES OF TAIWANOFUNGUS CAMPHORATUS}

The host specificity, scarcity in nature, and slow growth rate makes the large scale production of T. camphoratus very difficult. In the last decade, many scientists have tried to identify optimal culture conditions for mass production. Four major culture techniques have developed: submerged liquid fermentation, solid support culture, timber culture, and dish culture. Each culture method has its advantages and disadvantages. For example, the submerged fermentation technique can produce a great amount of $T$. camphoratus mycelia within 2-4 weeks, but the product contains less biologically active compounds. Both the timber and dish cultivations (Figure 2) produce $T$. camphoratus fruiting bodies with most of the biologically active compounds, but the growth of the former takes 0.5-2 years and the latter takes 4-6 months. Since biological activity differs between $T$. camphoratus originating from different cultivation methods and collections in the wild, it is necessary to clearly define the profiles of secondary metabolites and their biological functions to prevent confusion in the of T. camphoratus products.

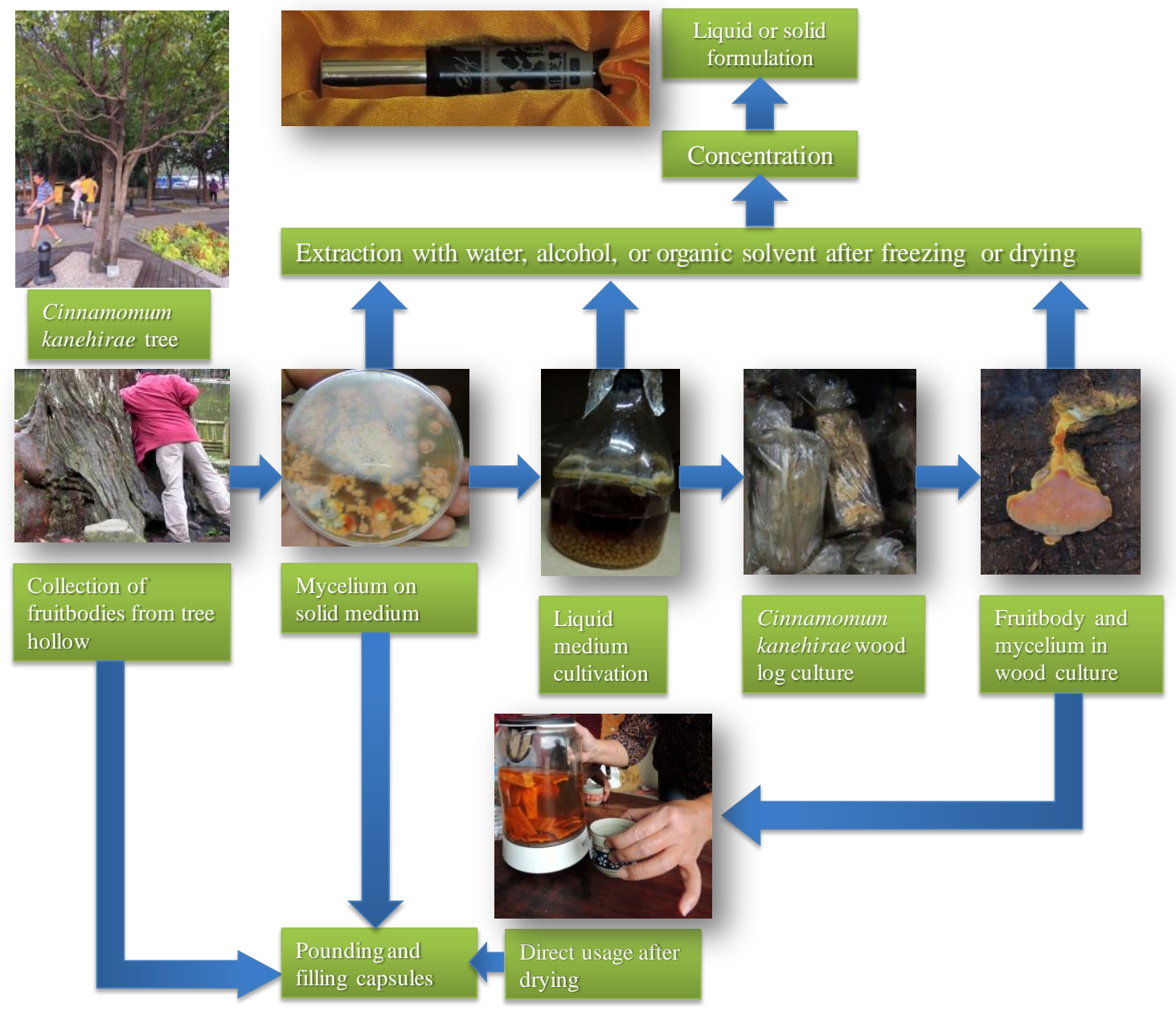

Figure 2. Processing of Taiwanofungus camphoratus from nature, liquid culture, solid culture and cultivation on wood of Cinnamomum kanehirae. 


\section{BIOACTIVE COMPOUNDS AND ANTI-CANCER MECHANISM}

The most studied biological activities of $T$. camphoratus are 1) anti-inflammatory activity; 2) cytotoxic activity; 3) hepato-protective activity; 4) antioxidant activity; 5) immune modulatory effect; and 6) miscellaneous activities, such as anti-allergic effect. The anti-cancer activity of $T$. camphoratus is a combination of its cytotoxic activity and immune modulatory effects.

Recently, in vivo and in vitro studies of the biological functions of $T$. camphoratus, using extracts or isolated pure compounds, against cancer or tumor cells revealed two mechanisms: the direct cytotoxic activity to inhibit cancerous growths and the stimulation of immune cells to enhance activity of both the innate and adaptive systems to eliminate pathogens or cancerous cells.

In general, the cytotoxic compounds can directly trigger cell apoptosis. The cytotoxic activity of a compound against testing cells is expressed through its half maximum inhibitory concentration $\left(\mathrm{IC}_{50}\right)$, which is the concentration of the compound that inhibits $50 \%$ population growth of the tested cells. When the experiment is conducted with both cancer and normal cells, the selectivity index (SI) is used to show the specificity of the drug against cancer cells in comparison to that of the normal cells. The SI was determined by the proportion of the $\mathrm{IC}_{50}$ value of cancer cells relative to that of normal cells.

The immune systems can be classified into the innate immune system (i.e. non-specific immune system or in-born immunity system), and adaptive immune system (also known as the acquired immune system or the specific immune system). The innate immune system is made up of cells and mechanisms that defend the host from infection by other organisms. The cells of the innate system recognize and respond to pathogens in a general way. The adaptive immune system is composed of highly specialized cells and processes to eliminate pathogens or prevent their growth. Natural killer (NK) cells hold an important role in immunity and chemo-preventive activity in human beings. They are crucial in innate immunity capturing viruses and killing cancer cells, as well as participating in adaptive immunity.

The innate immune system provides immediate defense against infection by: 1) recruiting immune cells to sites of infection through the production of chemical factors called cytokines; 2) activating the complement cascade to identify bacteria, activate cells, and promote clearance of antibody complexes or dead cells; 3) identifying and removing foreign substances present in organs, tissues, blood and lymph, by specialized white blood cells; 4) activating the adaptive immune system through a process known as antigen presentation; 5) acting as a physical and chemical barrier to infectious agents.

The adaptive immunity creates an immunological memory after an initial response to a specific pathogen, and leads to an enhanced response to subsequent encounters with that pathogen. 
This process of acquired immunity is the basis of vaccination. Like the innate system, the adaptive system includes both humoral immunity components and cell-mediated immunity components.

Some of these compounds are responsible for the stimulation of the immune system in a way that is shared by many medical mushrooms [18], while other compounds appear to be more specific to $T$. camphoratus and show specific cytotoxic activity against cancer cells. Many biologically active compounds have been isolated from $T$. camphoratus and some of the structures have been determined $[19,20]$. The most widely studied components among the numerous isolated compounds of $T$. camphoratus are: 1) antroquinonol and its derivatives; 2) succinic and maleic acid derivatives; 3) triterpenoids; 4) benzenoids; 5) polysaccharides; and 6) volatile essential oils.

Both polysaccharides and volatile essential oils have low cytotoxic activity against normal and cancerous cells. They can activate all the cells of the innate immune system, such as NK cells, and of the adaptive immune system, such as B cells. [21, 22].

\section{APPLICATION AND GLOBAL MARKETING}

Although the detailed procedure of manufacturing T. camphoratus for the market is the secret of companies, some basic information is presented (Figure 7). Fruitbodies collected in hollows of wild old trees of Cinnamomum kanehirae are considered the best for accompanying anticancer treatment. However, due to exorbitant prices and concerns of nature conservation the second choice of using fruitbodies from artificial cultivation on wood logs from plantations of $C$. kanehirae is an adequate alternative. Mycelia grown on wood logs or artificial solid substrates are considered the third choice. Mycelia grown in liquid culture are cheaper, particularly when they are not separated from the cultivation medium. Mycelia are less recommended for usage against cancer, but can be utilized in the treatment of less severe diseases and as health food.

Fruitbodies (or mycelia) are frozen or dried and can be extracted with hot water or organic solvents (alcohol) for direct uptake. In order to ensure standardized amounts, dried fruitbodies or mycelia are also powdered to be made into pressed tablets or filled into capsules, or their liquid extract is filled into small vials. Extracts provide the advantage that their compounds can be enriched by concentration and used conveniently as liquid or after spraying the highly concentrated extracts onto globuli also in solid form.

The total number of edible and medicinal fungi is over 2,300 species. Cultivated mushrooms have become popular with over 200 genera of useful macro-fungi in the world. According to the 
mushroom market reports 2017-trends, analysis, and statistics, the mushroom market will reach US\$50,034.12 million by 2019. Although there are no published figures related to the total world market value of medicinal mushrooms, the market value for Ganoderma medicinal mushroom in 1995 was estimated to be about US\$1,628.4 million [23]. The market values of the mushroom products were estimated to be US\$350 million in China, US\$600 million in Korea, US\$300 million in Japan, US\$215 million in Taiwan, US\$91.2 million in Malaysia, US\$60 million in Hong Kong, US\$2.2 million in Singapore and US\$10 million in other countries.

Medicinal mushrooms have emerged as integral ingredients of dietary supplements in the last few decades. It is estimated that between 80 and $85 \%$ of all medicinal mushrooms products are derived from the fruiting bodies, which have been either artificially cultured or collected from nature. The total market value of $T$. camphoratus products in Taiwan is estimated to be over US\$100 million per year (www. businesstoday.com.tw/article-content-80392-93594).

\section{SUMMARY}

Medically used macrofungi systematically belong to the orders Agaricales, Auriculariales, Boletales, Hymenochaetales, Polyporales, Russulales, and Tremellales of Agaricomycotina (Basidiomycota) and Hypocreales and Xylariales of Pezizomycotina (Ascomycota). Over 30 species have been identified as having anticancer activity.

Research regarding the taxonomy of the species is ongoing and not yet finished. Different strains of the same species and different parts of the same fungus can differ in their biologically active compounds.

Antitumor activity of fungal compounds is exhibited as cancer cell apoptosis, inhibition of cell growth, cell proliferation, and cancer cell metastasis, as well as altered gene or protein expression, indicating a high diversity of anticancer mechanisms.

Taiwanofungus camphoratus (synonym Antrodia cinnamomea) is an endemic polypore with red fruitbodies that is only formed on a tree of the laurel family also endemic to Taiwan. The fungus has commonly been used in ethnomedicine. Fruitbodies of T. camphoratus have the best effect while mycelium from liquid culture has the weakest effect.

Among the main groups of anticancer compounds of T. camphoratus $\gamma$-dodecalactone $(\gamma-$ DDL) and polysaccharides are mainly responsible for immunomodulatory effects, whereas 
cytotoxic effects are exerted by derivatives of antroquinonol as well as succinic and maleic acid, triterpenoids, and benzenoids. The triterpenoids are particularly highly specific for T. camphoratus and rich with respect to concentration and structural diversity.

T. camphoratus and other medicinal mushrooms play an increasing role in anticancer treatment and in the global market.

\section{ACKNOWLEDGEMENTS}

We thank the Herbarium of the National Research Institute of Chinese Medicine, Ministry of Health and Welfare, Taipei, Taiwan, for the permit to photograph specimens of Ophiocordyceps sinensis and Mr. Chen-Ching Chen, Taitung, Taiwan, to photograph Taiwanofungus camphoratus.

List of Abbreviations: 20-deoxy salinomycin, SY-1; a strain of white mouse, BALB/c mice; Bcell lymphoma 2, Bcl-2; Bcl-2-associated X protein, Bax; Cluster of Differentiation 69 (a human protein used as marker of early immune activation), CD69; cytotoxic concentration of a substance causing death to $50 \%$ of viable cells, $\mathrm{CC}_{50}$; deoxyribonucleic acid, DNA; fluorescein isothiocyanate/ propidium iodide, FITC/PI; $\gamma$-dodecalactone, $\gamma$-DDL; gas chromatography-mass spectrometry, GC-MS; half maximum inhibitory concentration, $\mathrm{IC}_{50}$; human breast cancer cell lines, MDA-MB-231 and MCF7; human colon cancer cell line, COLO 205; human glioblastoma cell lines, U87MG and GBM8401; human leukemia cancer cell line, HL-60; human liver carcinoma cell lines, Hep3B, HepG2 and Huh7; human liver cancer cell line marked with Enhanced Green Fluorescent Protein, HepG2-EGFP; human lung cancer cell line, A549; human oral squamous cell carcinoma cell lines, OC-2 and OEC-M; human prostate carcinoma cell lines, DU-145 and LNCaP; interphase arrested at fully grown cell stage, G0/G1 arrest; interphase and mitosis, G2/M phase; interphase (prior to DNA duplication) characterized by DNA fragmentation, sub-G1; messenger ribonucleic acid, mRNA; Michigan Cancer Foundation-7, MCF-7; micro ribonucleic acids, microRNAs; natural killer cells, NK cells; natural killer cells isolated from human peripheral-blood mononuclear cells, hPB-NK; neural cell adhesion molecule, CD56+; Poly (ADP-ribose) polymerase, PARP; selectivity index (proportion of the $\mathrm{IC}_{50}$ value of cancer cells relative to that of normal cells), SI; tricarboxylic acid cycle, TCA; terminal deoxynucleotidyl transferase dUTP nick end labeling, TUNEL.

Competing Interests: The authors declare no conflict of interest. 
Authors' Contributions: All authors contributed to this review.

\section{REFERENCES}

1. Capasso L: 5300 years ago, the Ice Man used natural laxatives and antibiotics. Lancet 1998, 352(9143): 1864.

2. Sekara A, Kalisz A, Grabowska A, Siwulski M: Auricularia spp. -mushrooms as Novel Food and therapeutic agents-a review. Sydowia 2015, 67:1-10.

3. Chang TT, Chou WN: Antrodia cinnamomea reconsidered and A. salmonea sp. nov. on Cunninghamia konishii in Taiwan. Botanical Bulletin of Academia Sinica Taipei 2004, 45(4):347-52.

4. Wu SH, Yu ZH, Dai YC, Chen CT, Su CH, Chen LC, Hsu WC, et al.: Taiwanofungus, polypore new genus. Fung Sci 2004, 19(3-4):109-16.

5. Hsieh YH, Chu FH, Wang YS, Chien SC, Chang ST, Shaw JF, Chen CY, et al.: Antrocamphin A, an anti-inflammatory principal from the fruitingbody of Taiwanofungus camphoratus, and its mechanisms. J Agric Food Chem 2010, 58(5):3153-8.

6. Tsai GH: Medical fungus: Antrodia cinnamomea. Mintong Medical Journal 1987, 127:7.

7. National Digital Library of Theses and Disserations in Taiwan [http://ndltd.ncl.edu.tw/cgibin/gs32/gsweb.cgi/ccd=S2s25./webmge?mode=]

8. Lu MC, El-Shazly M, Wu TY, Du YC, Chang TT, Chen CF, Hsu YM, et al.: Recent research and development of Antrodia cinnamomea. Pharmacology and Therapeutics 2013, $139(2): 124-56$.

9. Chen YF, Lu WL, Wu MD, Yuan GF: Analysis of Taiwan Patents for the Medicinal Mushroom "Niu-Chang-Chih". Recent Patents on Food, Nutrition and Agriculture 2013, 5(1):62-9.

10. Lu MY, Fan WL, Wang WF, Chen T, Tang YC, Chu FH, Chang TT, et al.: Genomic and transcriptomic analyses of the medicinal fungus Antrodia cinnamomea for its metabolite biosynthesis and sexual development. Proc Natl Acad Sci USA 2014, 111(44):E4743E4752.

11. Yang HL, Kuo YH, Tsai CT, Huang YT, Chen SC, Chang HW, Lin E, et al.: Antimetastatic activities of Antrodia camphorata against human breast cancer cells mediated through suppression of the MAPK signaling pathway. Food Chem Toxicol 2011, 49(1)290-8.

12. Hseu YC, Chen SC, Tsai PC, Chen CS, Lu FJ, Chang NW, Yang HL: Inhibition of cyclooxygenase- 2 and induction of apoptosis in estrogen-nonresponsive breast cancer cells by Antrodia camphorata. Food Chem Toxicol 2007, 45(7):1107-15. 
13. Hseu YC, Chen SC, Chen HC, Liao JW, Yang HL: Antrodia camphorata inhibits proliferation of human breast cancer cells in vitro and in vivo. Food Chem Toxicol 2008, 46(8):2680-8.

14. Chiang PC, Lin SC, Pan SL, Kuo CH, Tsai IL, Kuo MT, Wen WC, et al.: Antroquinol displays anticancer potential against human hepatocellular carcinoma cells: a crucial role of AMPK and mTOR pathways. Biochem Pharmacol 2010, 79(2):162-71.

15. Kumar VB, Yuan TC, Liou JW, Yang CJ, Sung PJ, Weng CF: Antroquinol inhibits NSCLC proliferation by altering PI3 K/mTOR proteins and miRNA expression profiles. Mutat Res 2011, 707(1-2):42-52.

16. Tsai WC, Rao YK, Lin SS, Chou MY, Shen YT, Wu CH, Geethangili M, et al.: Methylantcinate A induces tumor specific growth inhibition in oral cancer cells via Baxmediated mitochondrial apoptotic pathway. Bioorg Med Chem Lett 2010, 20(20):6145-8.

17. Hsu YL, Kuo PL, Cho CY, Ni WC, Tzeng TF, Ng LT, Kuo YH, et al.: Antrodia cinnamomea fruiting bodies extract suppresses the invasive potential of human liver cancer cell line PLC/PRF/5 through inhibition of nuclear factor kB pathway. Food Chem Toxicol 2007, 45(7):1249-57.

18. Kao C, Jesuthasan AC, Bishop KS, Glucina MP, Ferguson LR: Anti-cancer activities of Ganoderma lucidum: active ingredients and pathways. Functional Foods in Health and Disease 2013, 3(2):48-65.

19. Wang HC, Chu FH, Chien SC, Liao JW, Hsieh HW, Li WH, Lin CC, et al.: Establishment of the Metabolite Profile for an Antrodia cinnamomea Health Food Product and Investigation of Its Chemoprevention Activity. J Agric Food Chem 2013, 61(36):8556-64.

20. Qiao X, Song W, Wang Q, Liu KD, Zhang ZX, Bo T, Li RY, et al.: Comprehensive chemical analysis of triterpenoids and polysaccharides in the medicinal mushroom Antrodia cinnamomea. RSC Adv 2015, 5(58):47040-2.

21. Tsai CC, Yang FL, Huang ZY, Chen CS, Yang YL, Hua KF, Li J, et al.: Oligosaccharide and Peptidoglycan of Ganoderma lucidum Activate the Immune Response in Human Mononuclear Cells. J Agric Food Chem 2012, 60(11):2830-7.

22. Wang YZ, Zhang J, Zhao YL, Li T, Shen T, Li JQ, Li WY, et al.: Mycology, cultivation, traditional uses, phytochemistry and pharmacology of Wolfiporia cocos (Schwein.) Ryvarden et Gilb.: A review. Journal of Ethnopharmacology 2013, 147(2):265-76.

23. Chang ST: Products of Medicinal Mushrooms as a good source of dietary supplements. The international Society for Mushroom Science 2001, XV. 